\title{
O WALKTHROUGH NA AVALIAÇÃO DA ACESSIBILIDADE ESPACIAL EM UM CENTRO DE SAÚDE EM FLORIANÓPOLIS
}

\author{
PINTO, Carlos Fernando Machado (1); \\ DORNELES, Vanessa Goulart (2) \\ (1) Universidade Federal de Santa Catarina, Mestre \\ e-mail:arqcarlospinto@gmail.com \\ (2) Universidade Federal de Santa Maria, Doutora \\ e-mail: vavinhagd@gmail.com
}

\begin{abstract}
RESUMO
Este artigo trata da utilização do procedimento metodológico Walkthrough, para a análise dos ambientes dos ambientes internos e externos relacionados as questões de acessibilidade espacial do Centro de Saúde Jardim Atlântico, em Florianópolis. Foram realizados dois procedimentos de Walkthrough: o primeiro, walkthrough Técnico, feito pelo pesquisador. Observações feitas sob o ponto de vista técnico e focando apenas nas questões de acessibilidade espacial: orientação espacial, comunicação, deslocamento e uso. O segundo, walkthrough dos Funcionários, da própria instituição, realizados individualmente. O roteiro foi definido pelo pesquisador, que acompanhou os participantes e realizou registro por meio de áudio e fotografia.
\end{abstract}

Palavras chave: centro de saúde; acessibilidade espacial; walkthrough Técnico.

\begin{abstract}
This article deals with the use of the Walkthrough methodological procedure for the analysis of indoor and outdoor environments related to spatial accessibility issues at Jardim Atlântico Health Center in Florianópolis. Two Walkthrough procedures were performed: the first, Technical walkthrough, done by the researcher. Observations made from the technical point of view and focusing only on issues of spatial accessibility: spatial orientation, communication, displacement and use. The second, walkthrough of Employees, from the institution itself, performed individually. The script was defined by the researcher, who followed the participants and performed recording through audio and photography.
\end{abstract}

Keywords: health Center; spatial accessibility; technical walkthrough.

\section{INTRODUÇÃO}

As conquistas sociais garantidas pela Constituição Federal de 1988 (BRASIL, 1988), determinam como dever do Estado garantir saúde a toda população. Isso embasou a criação do Sistema Único de Saúde - SUS, um dos maiores sistemas públicos de saúde existentes no mundo, abrangendo desde simples procedimentos ambulatoriais até procedimentos como transplantes de órgãos. Este sistema incentiva o acesso integral, universal e gratuito aos seus serviços para toda a população do país (BRASIL, 2016), embora se saiba que este direito ainda não está garantido a todos os cidadãos brasileiros. 
De acordo com Decreto № 5.296 de 2 de Dezembro de 2004 (BRASIL, 2004), todas as edificações de uso público ou coletivo devem ser acessíveis as pessoas de modo que circulem com autonomia, segurança e de forma igualitária.

A importância das edificações públicas garantirem a acessibilidade de seus usuários aumenta quando estas edificações são destinadas a quem busca atendimento de saúde, muitas vezes pessoas com deficiências ou limitações e emocionalmente abatidas. A garantia do acesso da população ao sistema de saúde é definida pelo Decreto no 7.508, de 28 de julho de 2011 (BRASIL, 2011), que regulamenta a Lei no 8.080/90 garantindo, de modo igualitário, o acesso de todos os cidadãos ao SUS - onde os Centros de Saúde são a primeira instância de acesso de todos os cidadãos à rede de saúde pública nacional.

Considera-se que entre as principais edificações públicas estão aquelas de atendimento à saúde das pessoas, entre elas, os Centros de Saúde ${ }^{1}$, por serem locais que recebem uma diversidade de pessoas com diferentes capacidades e devem prever conforto e segurança a todos.

A acessibilidade é importante em todos os lugares, pois consiste em oportunizar que todas as pessoas acessem e utilizem com segurança e independência as edificações de maneira geral. O conceito de acessibilidade aproxima-se ao de cidadania, onde o direito constitucional de ir e vir (BRASIL, 1988) é a garantia de que todos os cidadãos tenham acesso à saúde, educação, trabalho, participando efetivamente da sociedade, com dignidade e sem distinção. A acessibilidade espacial deve ser então entendida como uma condição prevista no planejamento e execução de todos os espaços.

O objetivo deste artigo é o de avaliar os problemas relacionados à acessibilidade espacial do Centro de Saúde Jardim Atlântico, em Florianópolis a partir do método Walkthrough, sob a ótica de duas perspectivas: uma avaliação pautada em parâmetros técnicos e legais Walkthrough técnico, realizado pelo pesquisador, e uma avaliação sob a percepção das pessoas que utilizam diariamente esse ambiente de trabalho, com o Walkthrough dos funcionários.

Para tanto, o artigo está organizado com uma breve conceituação sobre a acessibilidade espacial, uma rápida explicação do método, os resultados obtidos pela avaliação e finalizando-se com a conclusão sobre a pesquisa elaborada.

\section{ACESSIBILIDADE ESPACIAL}

Para o entendimento do conceito de Acessibilidade Espacial e de suas aplicações em ações de avaliação e fiscalização dos mais diversos ambientes, Dischinger e Bins Ely (2009) identificaram quatro componentes constituídos por diretrizes que definem as características espaciais do ambiente de forma a permitir a acessibilidade sem restrições. O componente orientação espacial está relacionado com as informações arquitetônicas expressas no ambiente e que permita ao indivíduo se situar e se deslocar a partir das informações dadas pelo próprio ambiente. Estas informações podem ser extraídas a partir das formas, cores, disposição do mobiliário e também de informações adicionais gráficas - letreiros, mapas, pictogramas (DORNELES, ANDRADE e BINS ELY, 2011). Além da orientação espacial, outro importante componente de Acessibilidade Espacial é a comunicação, que corresponde à troca de informação entre os usuários e o ambiente e também a troca de informações interpessoais. A interação do usuário com o ambiente pode ser realizada com configurações espaciais e

\footnotetext{
${ }^{1}$ Os Centros de Saúdes são o primeiro nível de atendimento e têm como atribuição definida pela RDC 50/2002 a "prestação de atendimento eletivo de promoção e assistência à saúde em regime ambulatorial e de hospital dia". Existem outros Estabelecimentos Assistenciais de Saúde (EAS) que diferem do Centro de Saúde pela complexidade de atendimento como: atendimentos de urgência e de baixa e média complexidade e atendimento de saúde em sistema de internações (ANVISA, 2002).
} 


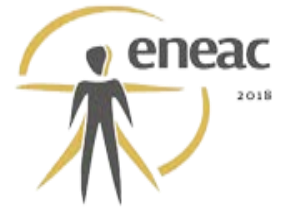

mobiliário adequado, podendo ser por meio de tecnologia assistiva, como telefones adaptados para pessoas com deficiência auditiva, ou terminais de computadores com programas para cegos, por exemplo. Para Andrade (2016) a comunicação pode ser empregada no sentido de transmitir uma informação que seja essencial para a realização de uma atividade que não seja diretamente ligada a uma orientação espacial em um ambiente.

O componente de deslocamento relaciona-se com a possibilidade de qualquer pessoa, independentemente de suas condições físicas, de mover-se de forma independente, com segurança e conforto. Outro componente de Acessibilidade Espacial identificado por Dischinger e Bins Ely (2009) se refere ao uso. Para Oliveira (2006) esse componente de acessibilidade trata da condição da possibilidade de se utilizar equipamentos e mobiliários e, com isso, participar das atividades. Estes devem ser acessíveis para a maior parte dos usuários e deverão ser manuseados com segurança, conforto e autonomia.

Estes quatro componentes possibilitam um entendimento das diferentes características dos ambientes que podem contribuir ou atrapalhar as condições de acessibilidade das pessoas de forma geral, e também permitem uma melhor sistematização das avaliações e soluções de acessibilidade.

\section{O ESTUDO DE CASO}

Para buscar a resposta sobre quais aspectos de acessibilidade devem ser prioritários em edificações voltadas para a saúde que garantam que as pessoas acessem os ambientes e realizem suas atividades com segurança, independência e de maneira igualitária, foi realizado um estudo de caso onde se aplicou uma avaliação pós-ocupação em um Centro de Saúde localizado no município de Florianópolis.

Neste artigo será apresentada a aplicação do procedimento Walkthrough, que objetivou captar a percepção de funcionários do Centro de Saúde e do pesquisador, frente aos problemas relacionados à Acessibilidade Espacial no estudo de caso

O procedimento metodológico chamado de walkthrough ${ }^{2}$ tem origem na psicologia ambiental ${ }^{3}$ (MOSER, 1998) e objetiva a possibilidade de o observador se familiarizar com a edificação em uso e com isso efetuar uma [...] "identificação descritiva dos aspectos negativos e positivos dos ambientes analisados". (RHEINGANTZ, AZEVEDO, et al., 2009, p. 12).

Páscoa (2008) considera que o Walkthrough deve ser um dos primeiros instrumentos de pesquisa a ser realizado, por identificar de maneira mais rápida e prática os principais problemas de um ambiente construído. Trata-se de um procedimento cujos resultados servem de embasamento para a aplicação posterior de outros procedimentos. O Walkthrough destaca-se como ferramenta de avaliação consagrada ao estabelecer:

[...] percurso dialogado abrangendo todos os ambientes, complementado por fotografias, croquis gerais egravações de áudio e de vídeo, possibilita que os observadores se familiarizem com a edificação, com a sua construção, com seu estado de conservaçãoe com seususos. (RHEINGANTZ, AZEVEDO, et al., 2009, p. 23).

Vale ressaltar que o diferencial deste método para avaliação de acessibilidade é possibilitar o uso de um roteiro ou percurso pré-determinado e com objetivo claro de avaliar determinados elementos ou situações no ambiente construído. Entretanto, por se tratar de um método onde a interação do pesquisador com o ambiente e com as pessoas é livre, há a possibilidade de

\footnotetext{
2 "Walkthrough - palavra da língua Inglesa que pode ser traduzida como passeio ou entrevista acompanhado. Em função do reconhecimento mundial, inclusive por parte dos pesquisadores brasileiros, foi mantida a sua designação original em Inglês." (RHEINGANTZ, AZEVEDO, et al., 2009, p. 21)

${ }^{3}$ Psicologia Ambiental: área interdisciplinar na qual se estuda a pessoa em seu contexto, tendo como tema central as inter-relações - e não somente as relações - entre a pessoa e o meio ambiente físico e social (MOSER, 1998).
} 


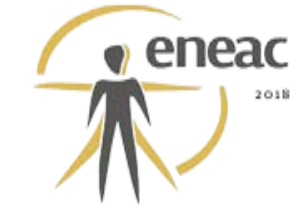

novas descobertas além daquilo que foi previamente determinado.

Buscando um melhor entendimento da percepção das pessoas sobre as condições de acessibilidade espacial no Centro de Saúde Jardim Atlântico e a obtenção de resultados com diferentes interpretações, foram realizados dois Walkthroughs: um de perfil mais técnico, pelo pesquisador, e outro com quatro funcionários da instituição.

\subsection{Walkthrough Técnico}

Para garantir neutralidade frente aos depoimentos dos demais participantes (funcionários), o primeiro procedimento do Walkthrough ${ }^{4}$ foi realizado pelo próprio pesquisador, inclusive em data anterior aos demais participantes. Embasado no Walkthrough de especialistas ${ }^{5}$ de Rheingantz (2009), as observações foram feitas sob o ponto de vista técnico e focando apenas às questões de acessibilidade espacial, observando-se os quatro componentes de acessibilidade já citados nesse artigo: orientação espacial, comunicação, deslocamento e uso.

A planta baixa do projeto arquitetônico do Centro de Saúde Jardim Atlântico, fornecido pela Secretaria de Saúde de Florianópolis, foi a base para a definição de um caminho a ser seguido pelo pesquisador para que, posteriormente, pudesse ser o percurso aplicado para os demais participantes. O gravador de áudio foi um facilitador do procedimento, já que não havia necessidade de parar o percurso para anotações em papel. Posteriormente foi realizada a transcrição dessa gravação. Com a máquina fotográfica foram efetuados os registros de imagens, que foram catalogadas e serviram posteriormente de apoio para a avaliação dos espaços.

Buscou-se um percurso que contemplasse a edificação externa e internamente, iniciando-se a caminhada pelo acesso principal para em seguida percorrer os espaços internos, observando os ambientes (Figura 1). Para otimizar o tempo, verificou-se apenas um dos consultórios indiferenciados, um dos consultórios diferenciados e um consultório odontológico, pois a similaridade de situação e mobiliário não justificaria observações repetidas.

Posteriormente foi realizada a tabulação dos dados colhidos a partir das observações feitas no Walkthrough Técnico. Para tanto, foi elaborado uma tabela contendo as principais barreiras encontradas pelo pesquisador relacionadas com os quatro componentes de acessibilidade. Para a sistematização dos dados foi organizada uma tabela (Tabela $1^{6}$ ) organizada em quatro colunas: a primeira com a nomenclatura do ambiente analisado, a segunda com as considerações feitas pelos participantes em relação às barreiras de acessibilidade espacial encontradas no ambiente, a terceira contendo uma imagem ilustrativa da avaliação, com a numeração correspondente relativa ao local onde foram feitas as fotografias e a quarta e última coluna, a referência do componente de acessibilidade espacial relacionado à barreira identificada pelo pesquisador. Também, para melhor entendimento do walkthrough técnico, foi inserido na planta baixa o percurso realizado (Figura 1).

\footnotetext{
${ }^{4}$ Denominado neste artigo como walkthrough técnico.

${ }^{5}$ Rheingantz (2009) define um Walkthrough Técnico como um walkthrough realizado por especialistas para examinar determinado conjunto de aspectos de um ambiente ou edifício. (RHEINGANTZ, AZEVEDO, et al., 2009, p. 27)

${ }^{6}$ A Tabela 1 é composta em um total de 36 ambientes avaliados. Neste artigo está exposto apenas um dos ambientes. A tabela completa está em Acessibilidade Espacial em Centros de Saúde de Florianópolis/SC: Um Estudo de Caso (PINTO, 2017)
} 


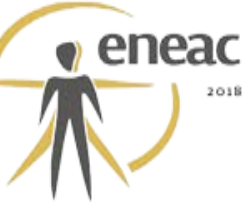

Figura 1 - Resultado Walkthrough Técnico

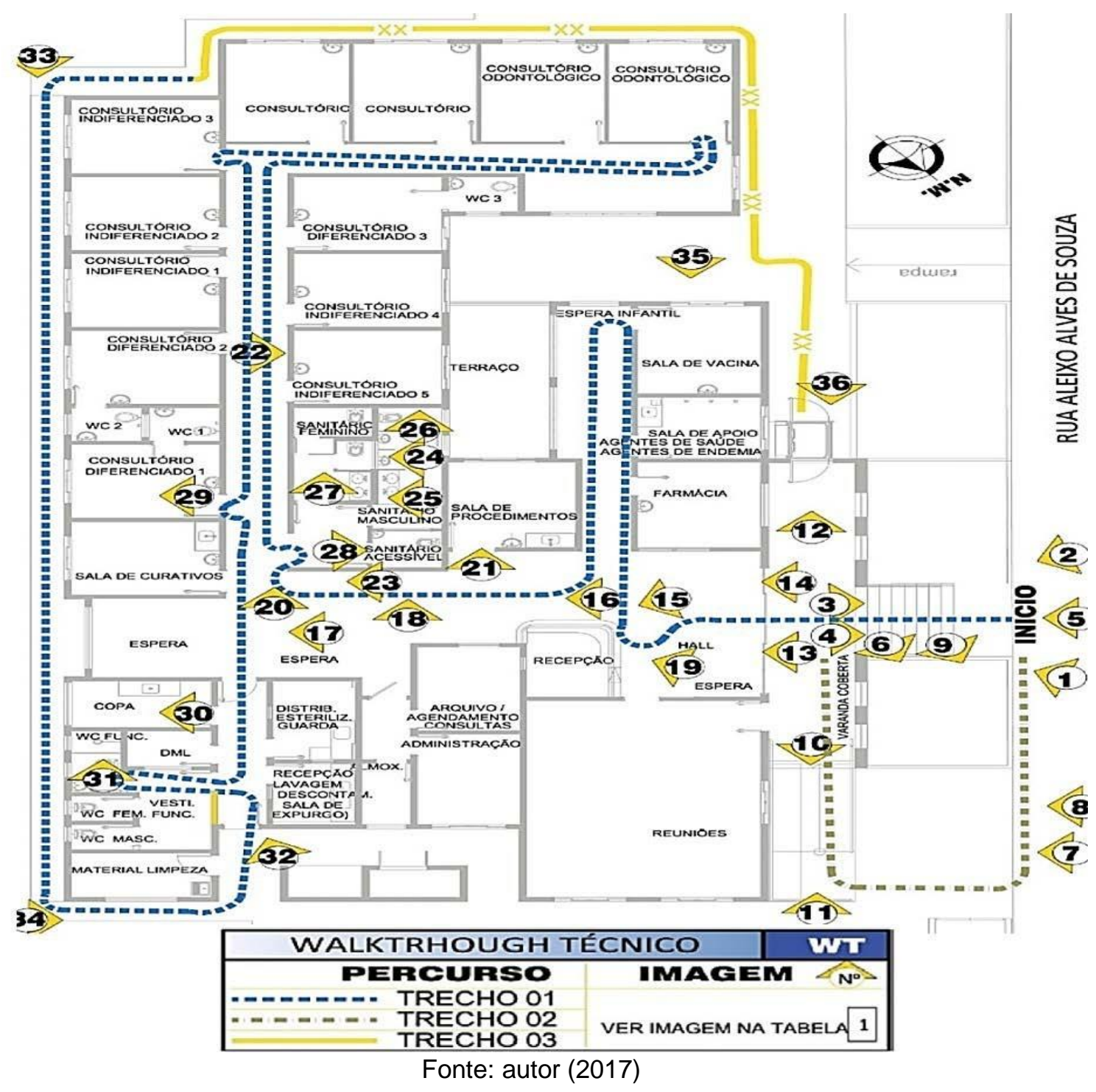

\subsection{Resultados Walkthrough Técnico}

O Walkthrough Técnico, por se tratar de uma avaliação elaborada por um especialista, apontou barreiras de acessibilidade relacionadas aos quatro componentes de acessibilidade.

No acesso principal (Tabela 1), uma das barreiras encontradas está relacionada ao componente de orientação espacial, visto que a calçada em frente ao edifício, inaugurado em Novembro de 2015, contém apenas a sinalização tátil de alerta e não a sinalização tátil direcional, portanto não se encontra adequado às diretrizes da Norma Brasileira NBR 16.537 de 27 de Junho de 2016 (ABNT, 2016), que trata da Sinalização Tátil no Piso. Outra barreira relevante encontrada neste primeiro trecho do walkthrough técnico está relacionada com o componente deslocamento, pois um fato recorrente observado durante todo o período de avaliação da edificação foi o trancamento do portão que dá acesso à rampa para pessoas com deficiência, impossibilitando, desta forma, o livre acesso. Ainda em relação ao deslocamento, no espaço que antecede a rampa verificou-se que não existe um espaço plano para que se possa chegar com um veículo e efetuar o desembarque de uma pessoa com cadeira de rodas e, ainda, com medições efetuadas foi possível identificar que a vaga não comporta o comprimento de um automóvel de médio porte. 
Tabela 1 - Resultado Walkthrough Técnico

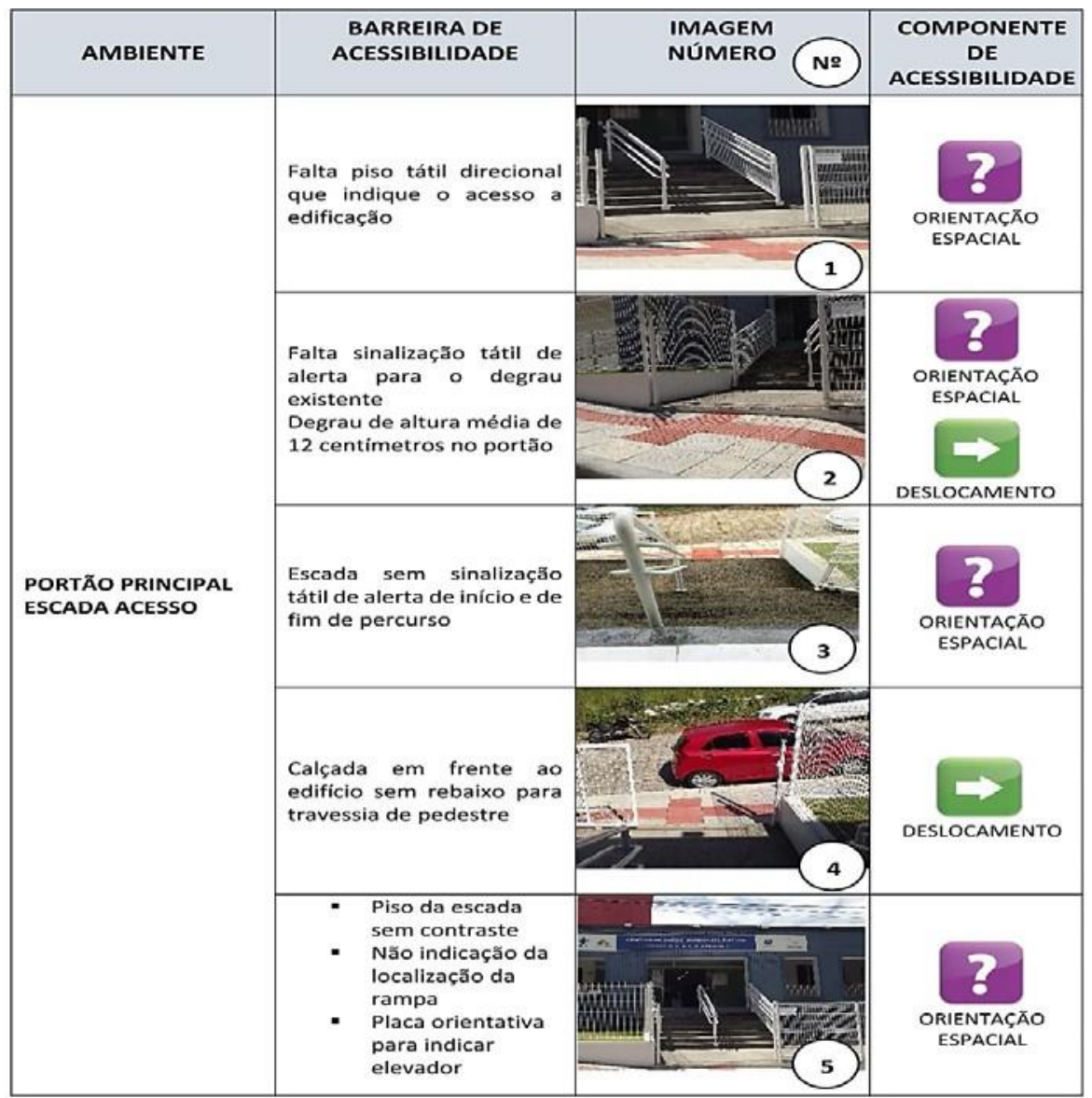

Fonte: arquivo pessoal (2017)

O hall coberto contempla a porta principal e dá acesso ao elevador de atendimento do pavimento inferior, onde está localizado o estacionamento do Centro de Saúde. Neste espaço verificou-se a presença de uma barreira de acessibilidade relativa ao uso. A porta principal de entrada encontra-se fechada e seu puxador não oferece condições de uma empunhadura adequada para sua abertura. Também nesse espaço, foram identificadas barreiras de acessibilidade referentes ao componente de comunicação, a inexistência de uma campainha para comunicação quando a porta encontra-se fechada e de orientações para pessoas com dificuldades visuais no elevador, inexistindo qualquer informação em Braille.

A recepção é um espaço amplo e para pessoas sem quaisquer dificuldades cognitivas, motoras ou sensoriais apresenta-se como um ambiente de boa legibilidade. Porém, uma observação técnica revela barreiras relevantes de orientação espacial como: a falta sinalização tátil de piso na mudança de direção nas circulações e a ausência de sinalização tátil de alerta junto aos mobiliários (bebedouro, mesas, guichês da farmácia e marcação de exames). Como barreira de comunicação, observa-se que a placa indicativa dos ambientes existentes trazem informações apenas no sentido visual, não existe informação em braile ou dispositivo sonoro permitindo que pessoas com restrições sensoriais obtenham as informações necessárias para o deslocamento nos ambientes do Centro de Saúde. Ainda neste ambiente, observou-se a inexistência de bancos para pessoas obesas, o que se configura como uma barreira de acessibilidade relacionada ao componente de uso.

As circulações também possuem carências informativas relacionadas ao componente de acessibilidade de orientação espacial, observadas na falta de pisos táteis indicativos, na falta de contraste de piso e parede, na inexistência de informações que indiquem, no cruzamento das circulações dos consultórios médicos e odontológicos, onde está a sala de espera e os 


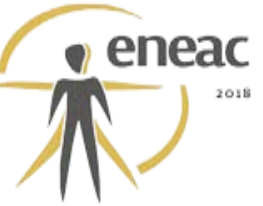

gabinetes odontológicos. Obstáculos no caminho, tais como: mesa de impressora, quadros de incêndio e brinquedos deveriam ser sinalizados para que não ocorram problemas de deslocamento dos usuários do Centro de Saúde.

Os consultórios de maneira geral apresentam tamanho apropriado, porém observa-se que o excesso de mobiliário dificulta o deslocamento de um cadeirante (figura 2).

Figura 2: Foto da configuração espacial do consultório avaliado.

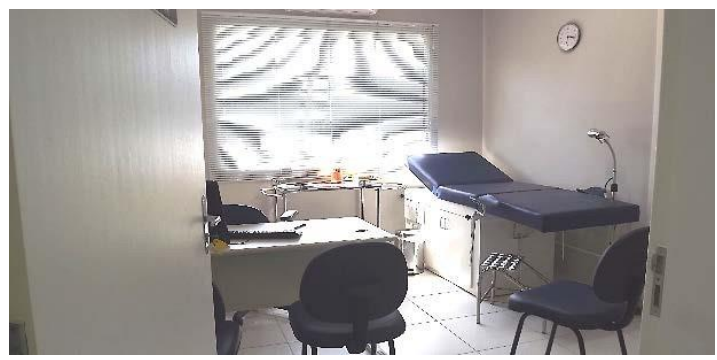

Fonte: arquivo pessoal (2017)

Os ambientes de sanitários apresentam barreiras relacionadas ao uso. Tanto no masculino como no feminino a altura do lavatório impede a aproximação e uso de uma pessoa com abaixa estatura ou mesmo uma criança. Os puxadores das portas dos gabinetes, igualmente, não oferecem uma empunhadura que permita facilidade no seu manuseio. Não há um espaço para trocador de fraldas, tanto infantil quanto adulto, nestes sanitários. No sanitário masculino os dois mictórios existentes não podem ser usados, pois estão lacrados com uma proteção de plástico por causa de odores produzidos no sistema de esgotamento sanitário desta unidade. No sanitário acessível há barras de apoio, porém inexistem barras verticais para uso de pessoas com diferentes estaturas.

No setor de uso restrito de funcionários, observam-se barreiras de deslocamento incluindo a copa com suas dimensões reduzidas, o degrau existente na soleira da porta de acesso de funcionários, e a existência de um capacho solto na mesma. Com relação a barreiras de uso, aponta-se a inexistência de barras de apoio no sanitário do vestiário que possibilite o uso por parte de pessoas com restrição de movimentos.

$\mathrm{O}$ acesso ao estacionamento do pavimento inferior pode ser feito pela rampa existente nos fundos do prédio. Porém há graves barreiras de deslocamento, pois a inclinação é inadequada e existem degraus neste percurso. Além disso, observa-se a falta de placas orientativas no percurso.

O pavimento de estacionamento apresenta barreiras relacionadas ao uso, decorrentes da inexistência de marcação de vagas para pessoas com deficiência e também para os idosos. As barreiras informacionais mais significativas neste ambiente são referentes ao equipamento do elevador, pois há falta de uma sinalização tátil de alerta e ausência de placa com identificação do pavimento. Não há botoeira do elevador em Braille e nenhuma comunicação direta com a recepção.

\subsection{Walkthrough dos Funcionários ${ }^{7}$}

$\mathrm{Na}$ segunda etapa deste procedimento foram realizados análises walkthrough com funcionários do Centro de Saúde, pessoas que desenvolvem diariamente suas atividades profissionais neste local. O objetivo foi buscar informações dessas pessoas sobre questões

\footnotetext{
${ }^{7}$ Foi denominado Walkthrough dos Funcionários por este procedimento ter sido realizado apenas com funcionários do Centro de Saúde.
} 


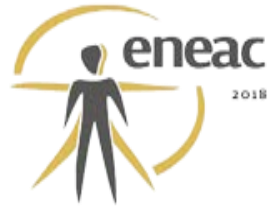

de acessibilidade espacial, pois o apontamento de barreiras de acessibilidade por pessoas com pleno conhecimento e uso do ambiente do estudo de caso possibilita entender a dinâmica do espaço na apropriação e no cuidado com outras pessoas que possam apresentar alguma limitação ou restrição na interação com os ambientes.

Para uma amostragem mais significativa, foi elaborada uma composição de participantes de distintas funções. Assim sendo, participaram do walkthrough, uma médica, uma auxiliar de serviços gerais, uma auxiliar de enfermagem e um dentista, totalizando quatro funcionários.

Assim como no walkthrough técnico, as observações dos participantes quanto à acessibilidade espacial no Centro de Saúde Jardim Atlântico (Figura 3) foram posteriormente tabuladas e inseridas em quadro semelhante ao descrito anteriormente, sempre relacionando essas observações com os quatro componentes de acessibilidade (Tabela $2^{8}$ ).

Figura 3 - Percurso Walkthrough Funcionários

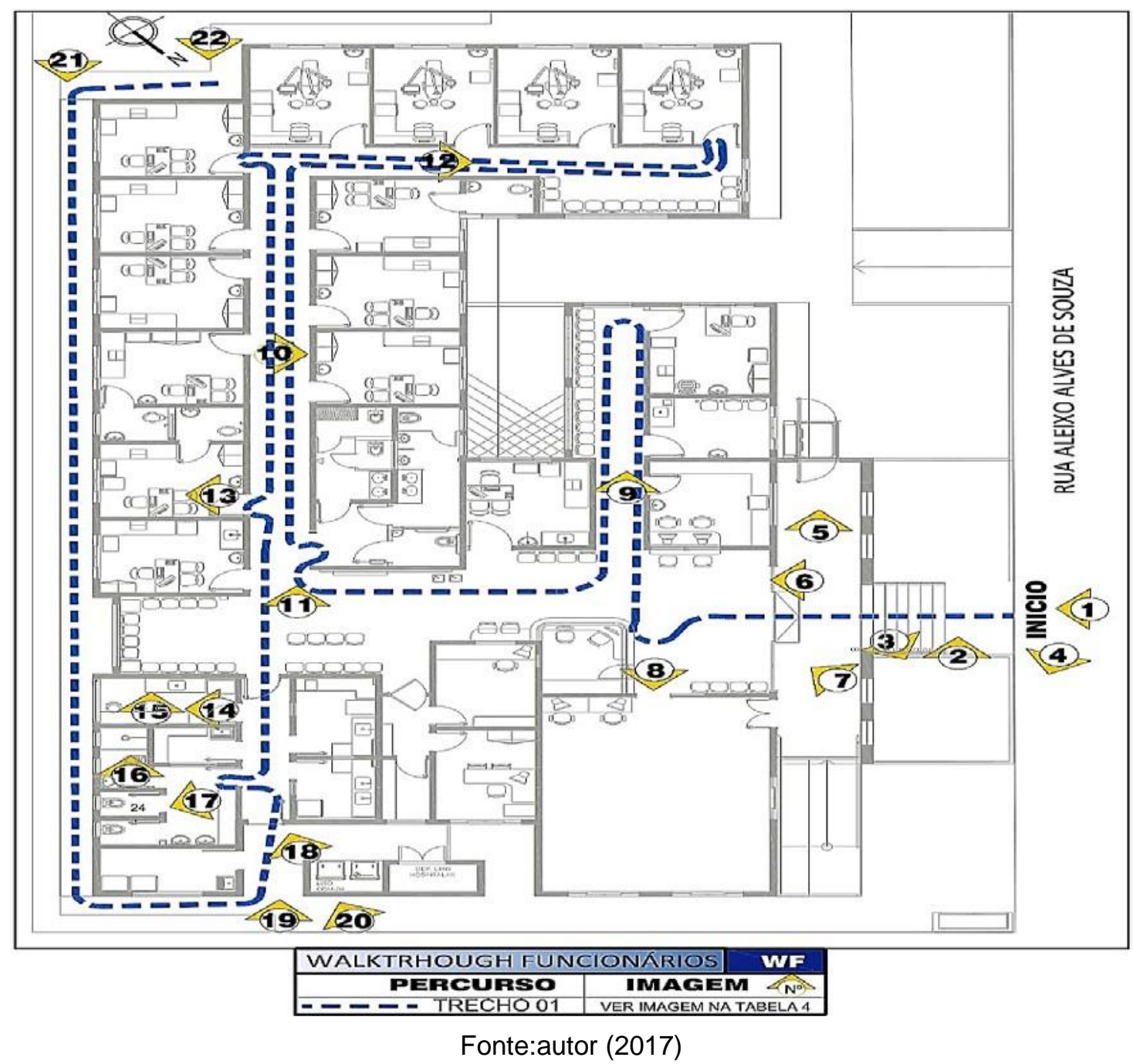

${ }^{8}$ A Tabela 2 é composta em um total de 22 ambientes avaliados. Neste artigo está exposto apenas um dos ambientes. A tabela completa está em Acessibilidade Espacial em Centros de Saúde de Florianópolis/SC: Um Estudo de Caso (PINTO, 2017) 


\subsection{Resultados Walkthrough Funcionários}

Diferentemente do Walkthrough técnico, este procedimento resgata as observações dos funcionários sobre a acessibilidade espacial no Centro de Saúde Jardim Atlântico frente às situações em que foram detectadas barreiras de acessibilidade. As diferentes funções exercidas pelos participantes neste estabelecimento assistencial de saúde dão ao experimento uma diversidade de informações que enriquecem as observações frente às barreiras de acessibilidade encontradas.

Nesta atividade específica observou-se que as maiores contribuições foram dos funcionários que exercem funções que demandam contato com todos os ambientes do Centro de Saúde.

O acesso à edificação marca a primeira intervenção de um dos participantes que verbaliza "a rampa está muito distante da escada", ao observar o distanciamento entre o acesso principal e a rampa construída para pessoas com restrição de mobilidade, caracterizando uma barreira que dificulta o deslocamento e a orientação espacial. Ainda neste espaço foi constatada a falta de um revestimento de piso que oriente o acesso ao Centro de Saúde. Outra barreira constatada está relacionada ao fato do portão de acesso à rampa ficar constantemente fechado, impedindo o livre acesso de pessoas com restrição de mobilidade. Este portão, por motivos de segurança, fica trancado e somente é aberto quando há demanda para o seu uso. Foi observado também que o pátio que antecede a rampa não é plano. Neste local há espaço para que um veículo se aproxime da rampa e efetue o desembarque de uma pessoa com mobilidade reduzida, porém a declividade da rua e da calçada criam dificuldades para se operacionalizar este desembarque com segurança e, consequentemente, o deslocamento do cadeirante.

No acesso principal (Tabela 2), foram observadas algumas barreiras de deslocamento, como por exemplo, o fato de o elevador não ser utilizado ${ }^{9}$ por problemas de manutenção. O degrau na soleira também foi apontado como uma dificuldade de deslocamento para pessoas com cadeira de rodas ou mesmo idosos.

Sobre os espaços de circulação existentes, os participantes consideraram que poderiam ser mais largos, facilitando o deslocamento dos usuários. Também afirmaram que equipamentos não deveriam estar localizados nestes ambientes, como brinquedos e impressoras. Uma barreira de comunicação observada foi o distanciamento físico entre a sala de espera e os consultórios. Muitas vezes o profissional tem que sair do consultório ${ }^{10}$ e deslocar-se até a circulação para chamar o paciente.

Por ser um procedimento realizado pelos funcionários que atuam na instituição, os espaços de uso exclusivo de funcionários foram por eles avaliados. Foram apontadas barreiras relacionadas ao uso e ao deslocamento, principalmente na copa, onde se constatou espaço reduzido e armários muito altos, ocasionando barreiras relacionadas ao deslocamento e também ao uso. A ausência de barras de apoio no sanitário do vestiário e local para que se possa sentar no vestiário são apontadas como barreiras de uso nestes ambientes. O degrau existente na soleira da porta de acesso dos funcionários foi considerado como obstáculo para

\footnotetext{
${ }^{9}$ Questionados sobre o uso do elevador existente no Centro de Saúde Jardim Atlântico, todos os quatro participantes do Walkthrough dos Funcionários relataram que desde que começaram a trabalhar neste local, ou seja, desde a inauguração do Centro, nunca viram o elevador funcionando. Aqui observa o pesquisador que a data de inauguração do Centro de Saúde foi no dia 22 de Setembro de 2015 e a data da realização do procedimento foi dia 22 de Novembro de 2016, portanto quatorze meses sem que o equipamento tenha sido utilizado.

${ }^{10} \mathrm{~A}$ sala de espera dos consultórios odontológicos encontra-se em local distante e de pouca visibilidade para quem frequenta o Centro de Saúde. Muitas vezes os pacientes aguardam ser chamados na sala de espera dos consultórios médicos. Os dentistas então tem que se deslocar até o encontro da circulação dos consultórios odontológicos com a circulação dos consultórios médicos para fazer o chamamento do paciente para o atendimento.
} 


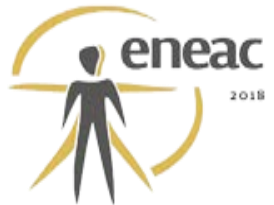

uma pessoa acessar o prédio.

No percurso existente entre 0 acesso dos funcionários e o estacionamento ${ }^{11}$ foram apontadas barreiras de deslocamento, como o degrau existente e também a acentuada inclinação da rampa. Outra barreira encontrada foi a mureta existente ao redor do estacionamento, que dificulta o deslocamento entre o veículo estacionado e a rampa dos fundos.

\section{Tabela 2 - Resultado Walkthrough dos Funcionários}

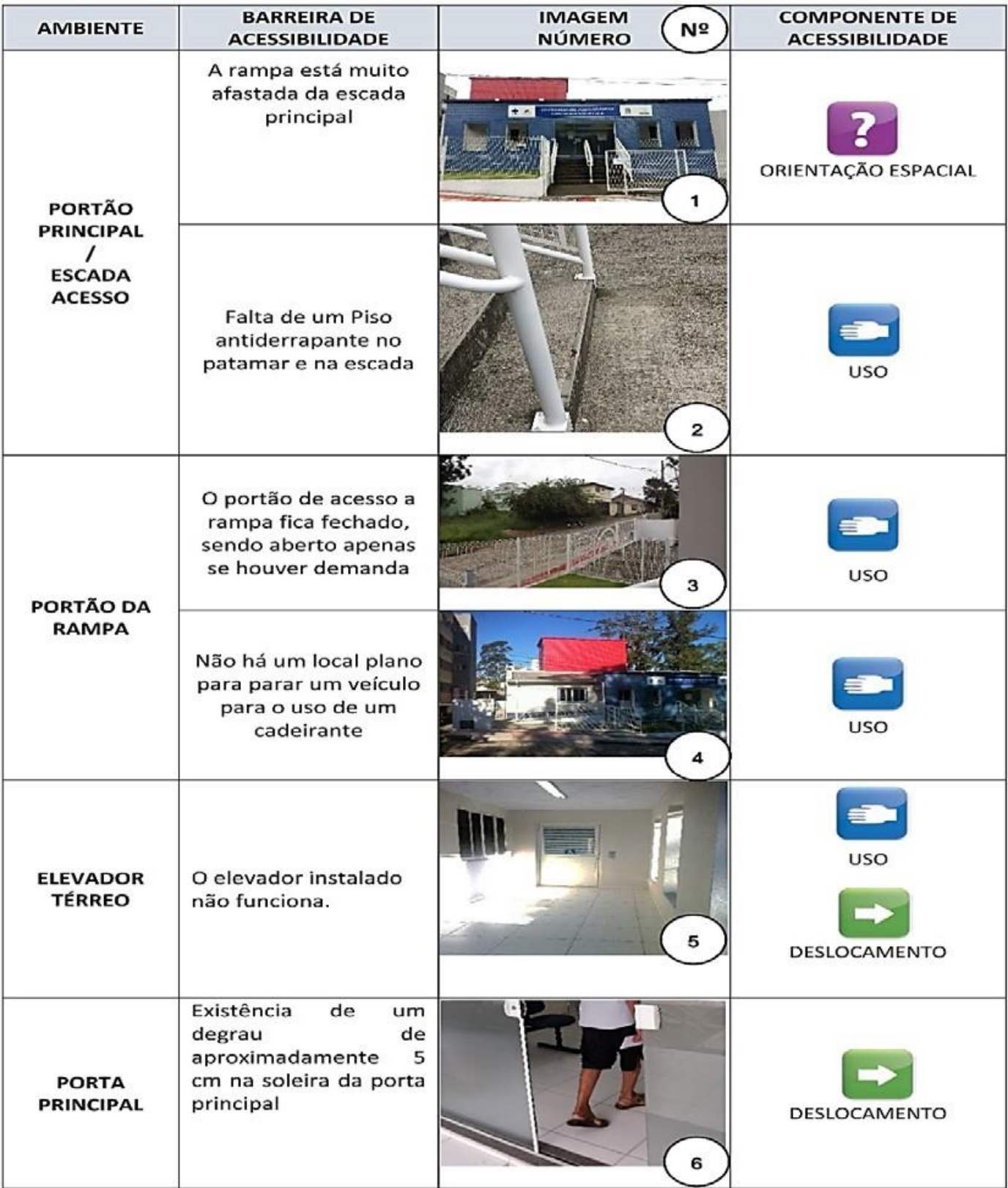

Fonte: Arquivo pessoal (2017)

\subsection{Considerações gerais sobre a aplicação do walkthrough}

Com a aplicação do Walkthrough foi possível constatar problemas relacionados à

\footnotetext{
${ }^{11}$ Nem todos os participantes do Walkthrough dos funcionários utilizam o estacionamento localizado no pavimento inferior. Apenas os que fazem o uso deste espaço é que participaram deste trecho do procedimento.
} 
acessibilidade espacial sob a percepção das pessoas que utilizam diariamente esse ambiente de trabalho, bem como, pela percepção do próprio pesquisador.

O Walkthrough técnico, por ter sido realizado por um especialista, portanto com base em conhecimento científico, técnicas projetuais, normas técnicas e legislações, avalia os ambientes de maneira mais ampla, tanto que demorou mais tempo para ser realizado, observando todos os aspectos relacionados à acessibilidade espacial na edificação. Desta forma, foram verificadas as barreiras existentes relacionadas aos quatro componentes de acessibilidade espacial: orientação espacial, comunicação, deslocamento e uso.

As avaliações feitas no Walkthrough dos Funcionários, trouxeram importantes contribuições relacionadas à acessibilidade espacial deste Centro de Saúde. Constata-se que a orientação espacial obteve uma avaliação pouco significativa, provavelmente pelo fato destes participantes serem funcionários do local e terem contato diário com os ambientes. Os problemas mais relevantes na percepção da equipe de saúde foram os relacionados ao uso e também ao deslocamento.

Importante observar que as informações colhidas nos dois procedimentos realizados, o Walkthrough dos funcionários e o Walkthrough técnico, embora apresentem diferenças, são complementares, pois algumas observações feitas pelos funcionários, como por exemplo, a inadequação do puxador da sala de reuniões, não foi observado pelo pesquisador. Do mesmo modo, a constatação por parte do pesquisador da inexistência de assento para obesos na sala de espera da recepção não foi observado pelos funcionários.

Por fim, destaca-se uma observação significativa feita por um dos participantes, funcionário terceirizado, ao avaliar que a rampa para pessoas com restrições de mobilidade deveria estar junto à escada principal de acesso. Tal observação demonstra que este participante carrega intrinsicamente a percepção da necessidade do uso de espaço equitativo e sem segregação, um dos pilares de uma arquitetura que se propõe centrada no ser humano.

\section{CONCLUSÃO}

A aplicação do procedimento Walkthrough permitiu captar a percepção das pessoas sem restrições ou deficiências, tanto de funcionários do Centro de Saúde como do pesquisador, frente aos problemas relacionados à Acessibilidade Espacial no estudo de caso.

O Walkthrough técnico, por estar pautado em conhecimentos técnicos e legais, apontou um número maior de barreiras relacionadas aos quatro componentes de acessibilidade, diferente do Walkthrough dos funcionários. Com este último, constatou-se que a orientação espacial obteve uma avaliação pouco significativa, influenciada provavelmente pelo conhecimento prévio dos ambientes por parte dos participantes. Estes mesmos participantes não apontaram barreiras de comunicação ao realizar as atividades. Por outro lado, as barreiras relacionadas ao uso e deslocamento foram mais relevantes.

Por fim, a contribuição deste procedimento para o trabalho se justifica pela complementação de dados levantados pela avaliação técnica e legal, conferida pelo Walkthrough técnico, com dados levantados na observação das barreiras de acessibilidade diariamente constatadas pelas pessoas que trabalham no local, conferida pelo Walkthrough dos funcionários.

Vale ressaltar que este artigo retratou a utilização de um dos métodos para avaliação de acessibilidade que permitiu um panorama geral sobre o ambiente construído e suas dinâmicas. Entretanto, outros métodos são necessários para uma avaliação de acessibilidade mais completa, como por exemplo a utilização de planilhas de acessibilidade baseadas nas normas de acessibilidade e os passeios acompanhados. Vale ressaltar, portanto, que este artigo é parte de uma pesquisa de mestrado que já encontra-se concluída, com o título: ACESSIBILIDADE ESPACIAL EM CENTROS DE SAÚDE EM FLORIANÓPOLIS/SC: UM ESTUDO DE CASO. 


\section{REFERÊNCIAS BIBLIOGRÁFICAS}

ABNT, A. B. D. N. T. NBR 16.537: Sinalização tátil no piso - Diretrizes para elaboração de projetos e instalação. Rio de Janeiro: [s.n.], 2016.

ANDRADE, I. F. Sistema Informacional para a orientação Espacial em Terminais Aeroportuários a partir das Estratégias Adotadas pelos Indivíduos. Florianópolis: Tese (Doutorado em Arquitetura e Urbanismo) - Programa de Pós Graduação, UFSC, 2016.

ANVISA. RDC 50. Dispõe sobre o Regulamento Técnico para planejamento, programação, elaboração e avaliação de projetos físicos de estabelecimentos assistenciais de saúde2. Agência Nacional de Vigilância Sanitária. BRASILIA. 2002.

BRASIL. Decreto no 5.296 de 2 de dezembro de 2004: Regulamenta as Leis nos 10.048, de 8 de novembro de 2000, que dá prioridade de atendimento às pessoas que especifica, e 10.098, de 19 de dezembro de 2000, que estabelece normas gerais e critérios básicos para a p. Brasilia: Diário Oficial [da] República Federativa do Brasil, 2004.

BRASIL. DECRETO № 7.508, DE 28 DE JUNHO DE 2011-organização do Sistema Único de Saúde - SUS, o planejamento da saúde, a assistência à saúde e a articulação interfederativa. Brasilia: [s.n.], 2011.

BRASIL, M. D. S. Portal da saúde. Portal da saúde, 2016. Disponivel em: <http://portalsaude.saude.gov.br/index.php/o-ministerio/estrutura-e-competencias\#>. Acesso em: 5 agosto 2016.

BRASIL, S. F. Constituição Federal. [S.I.]: [s.n.], 1988.

DISCHINGER, M.; BINS ELY, V. H. M.; BORGES, M. M. F. D. C. Manual de Acessibilidade Espacial para Escolas: o direito à escola acessível. Brasilia: Ministério da Educação,Secretaria de Educação Especial, 2009.

DORNELES, V. G.; ANDRADE, I. F.; BINS ELY, V. H. M. Artigo publicado no V Seminário Nacional sobre Ensino e Pesquisa em Projeto de Arquitetura - PROJETAR 2011 -, Belo Horizonte/MG, 2011.

MOSER, G. Psicologia ambiental Palestra proferida na Biblioteca Central da Universidade Federal do Rio Grande do Norte, Natal, RN, em 27 de agosto de 1997. Estudos de Psicologia (Natal), Natal , v. 3, Jan./June 1998. ISSN 1.

OLIVEIRA, A. S. D. A. D. Acessibilidade Espacial em Centro Cultural: Estudo de Casos. [S.I.]: Dissertação (Mestrado em Arquitetura e Urbanismo) - Programa de Pós Graduação, UFSC, 2006.

PÁSCOA, O. N. D. F. A Qualidade do Lugar em Escola Pública padronizada do Rio de Janeiro. Estudo de caso: Escola Municipal Tia Ciata. Rio de Janeiro: Dissertação (mestrado) - UFRJ/PROARQ - Programa de Pós-Graduação em Arquitetura, 2008.

PINTO, C. F. M. ACESSIBILIDADE ESPACIAL EM CENTROS DE SAÚDE EM FLORIANÓPOLIS/SC: UM ESTUDO DE CASO. Florianópolis SC: Dissertação (Mestrado em Arquitetura e Urbanismo) Programa de Pós Graduação, UFSC. 318 p, 2017.

RHEINGANTZ, P. A. et al. Observando a qualidade do lugar: procedimentos para a avaliação pósocupação. Rio de Janeiro: Coleção PROARQ: FAU-UFRJ, 2009. 